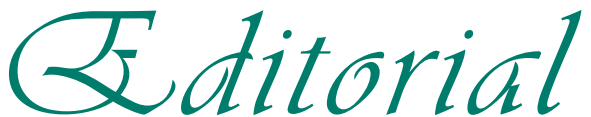

\section{Publicar: ¿para qué?}

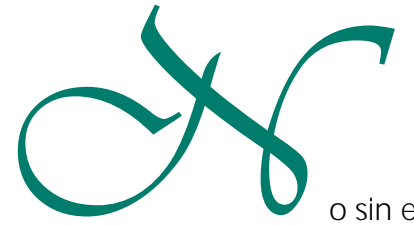

o sin esfuerzo tenemos entre manos y podemos leer este nuevo número dedicado a Prótesis Estomatológica. Digo no sin esfuerzo, pues ha sido arduo recopilar los cinco artículos que lo componen; gracias a una petición previa a los autores y a su desinteresado esfuerzo ha sido posible que viera la luz en forma y tiempo. Animo desde estas líneas a todos los lectores para que envien algún trabajo de investigación o no de contenido protésico de interés y de acuerdo a las normas de publicación. La realidad es que en la redacción de la revista, se recibe de tarde en tarde alguno pero en cantidad insuficiente para componer un número con la periocidad deseada.

No quiero pensar y menos escribir que la Prótesis Estomatológica como doctrina y terapéutica haya llegado a su máximo nivel donde no haya nada que contrastar, discutir o aclarar. Dentro de su amplitud en técnica, materiales, instrumental y praxis clínica existen innumerables aspectos y cuestiones que necesitan ser revisados, aclarados y certificados con rigor científico. Más bien sospecho que nos hemos instalado en la comodidad de la practica clíni$\mathrm{ca}$, de dejar las dudas y los problemas para que los resuelvan los demás; del tan clásico «que investiguen ellos», para asumir sólo los beneficios. $\mathrm{O}$ al contrario, nuestra producción científica protésica es importante, pero el numero, calidad y difusión de las revistan que lo soportan son tantas y tan importantes que no hay suficiente producción para todas. Quizás sea así, pero la RCOE es recibida por todos los colegiados, luego de amplia difusión en nuestro

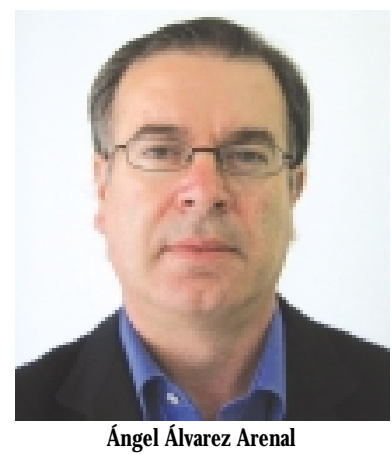

país, y además figura en bases de datos importantes, como para ser tenida en cuenta como primera opción exceptuando por supuesto aquellas que tengan factor de impacto.

Así y todo este número contiene tres artículos originales donde se analiza en uno los posibles cambios de apreciación de color en superficies cerámicas pulidas después del glaseado, situación frecuente en clínica concluyendo que existen diferencias de color más o menos marcadas dependiendo del tipo de luz, cerámica, aleaciones y color elegidos. Otro nos aclara que la referencia bioscópica más paralela al plano oclusal es el plano de Camper trazado uniendo el ala de la nariz con la parte inferior del trago a la vez que argumenta sobre su interés clínico en relación a la altura coronal de los dientes superiores; $y$ en el tercero, la angulación de las fibras del músculo masetero con el plano oclusal para conseguir una mayor eficacia funcional. El resto de contenidos lo cierra una revisión crítica sobre un tema de actualidad como es la cerámica sin metal y un caso clínico atípico en la consulta pero no exento de interés como es la construcción de una prótesis oculo-palpebral.

Un saludo a todos y ánimo para redactar artículos, revisiones, casos clínicos y todo aquello que sea pertinente y susceptible de ser publicado en un próximo número dedicado a la Prótesis Estomatológica.

Ángel Álvarez Arenal Director Asociado RCOE 